\title{
Importance of Fixation Angle in Posterior Instrumented Occipitocervical Fusion
}

\author{
-Technical Note-
}

\author{
Toshihiro TAKAMI, Tsutomu ICHINOSE, Kenichi ISHIBASHI, \\ Takeo GOTO, Naohiro TsuYuguCHI, and Kenji OHATA
}

Department of Neurosurgery, Osaka City University Graduate School of Medicine, Osaka

\begin{abstract}
Occipitocervical fusion with the head in a functionally neutral position is critically important. Various methods have been proposed for measuring the angle of the craniovertebral junction based on lateral radiography. We describe a simple and reliable measurement of fixation angle during occipitocervical fusion using the line parallel to the bony palate and the posterior longitudinal line of the C2 vertebra. The normal range of the angle of the craniovertebral junction was measured in 30 normal healthy volunteers, 15 males and 15 females aged from 17 to 77 years (mean 45.1 years), without symptoms of neck pain or limitations of neck movement. The angle ranged from 85 to 118 degrees. The mean angle was 97.1 degrees in males and 102.6 degrees in females, with overall mean \pm standard deviation of 99.9 \pm 8.1 degrees. Careful adjustment of the angle of the craniovertebral junction can help to avoid postoperative complications such as dysphagia, dyspnea, and subaxial subluxation.
\end{abstract}

Key words: dysphagia, dyspnea, fixation angle, occipitocervical fusion, posterior instrumented fusion

\section{Introduction}

Occipitocervical fusion with the head in a functionally neutral position is critically important, as various functional and mechanical complications may occur after occipitocervical fusion. ${ }^{6,8-10,15)}$ Upper airway obstruction after posterior cervical fusion has been recognized as a serious postoperative complication caused by a reduction in the oropharyngeal space. ${ }^{6,8)}$ The etiology is complex, but the fixation angle is an important factor. Occipitocervical fusion in a flexed position results in further narrowing of the pharynx at the laryngeal inlet, and symptoms have been relieved after changing the fixation angle of the occipitocervical spine..$^{6,9,15)}$

The occipitoaxial angle in occipitocervical fusion is also important to avoid postoperative subaxial subluxation, which appears to be a result of the mechanical effects of fusion. A study of 38 patients with rheumatoid arthritis who underwent occipitocervical fusion for atlantoaxial dislocation and who were followed up for more than 5 years after

Received August 30, 2007; Accepted January 23, 2008 surgery found subaxial subluxation was significantly more common in patients with flexed angle of the craniovertebral junction than in patients with normal or extended angle. ${ }^{10)}$ Fusion of these segments in a poor position may reduce the ability of the subaxial spine to compensate and maintain the head in a neutral position. Malposition between the occiput and axis may also result in narrowing of the space for the spinal cord at the foramen magnum and can lead to neurological disorders.

Surgery such as atlantoaxial or occipitocervical fusion has become more common with the development of various surgical instrumentation and navigation systems. ${ }^{1-5,7,14)}$ Various methods are available to measure the angle of the craniovertebral junction based on lateral radiography. ${ }^{11-13)}$

Here we describe a simple and reliable measurement of fixation angle during occipitocervical fusion.

\section{Patients and Methods}

Occipitocervical fusion was performed in six patients over the past 3 years. The basic principle of our approach to posterior instrumented occipitocer- 
Table 1 Clinical summary of 6 patients with occipitocervical instability treated over the past 3 years

\begin{tabular}{cccllll}
\hline $\begin{array}{c}\text { Case } \\
\text { No. }\end{array}$ & $\begin{array}{c}\text { Age } \\
\text { (yrs) }\end{array}$ & Sex & Chief complaint & Disease category & Fusion level & $\begin{array}{c}\text { Postoperative dysphagia } \\
\text { or dyspnea }\end{array}$ \\
\hline 1 & 63 & M & gait disturbance & degenerative disease & occipital-C2 & - \\
2 & 57 & F & gait disturbance & basilar invagination & occipital-C4 & - \\
3 & 40 & F & neck pain & trauma & occipital-C2 & - \\
4 & 72 & F & neck pain & tumor & occipital-C4 & $+{ }^{*}$ \\
5 & 44 & M & neck pain & tumor & occipital-C2 & - \\
6 & 11 & M & neck pain & basilar invagination & occipital-C2 & - \\
\hline
\end{tabular}

${ }^{*}$ Caused by tumor invading the lower cranial nerves.
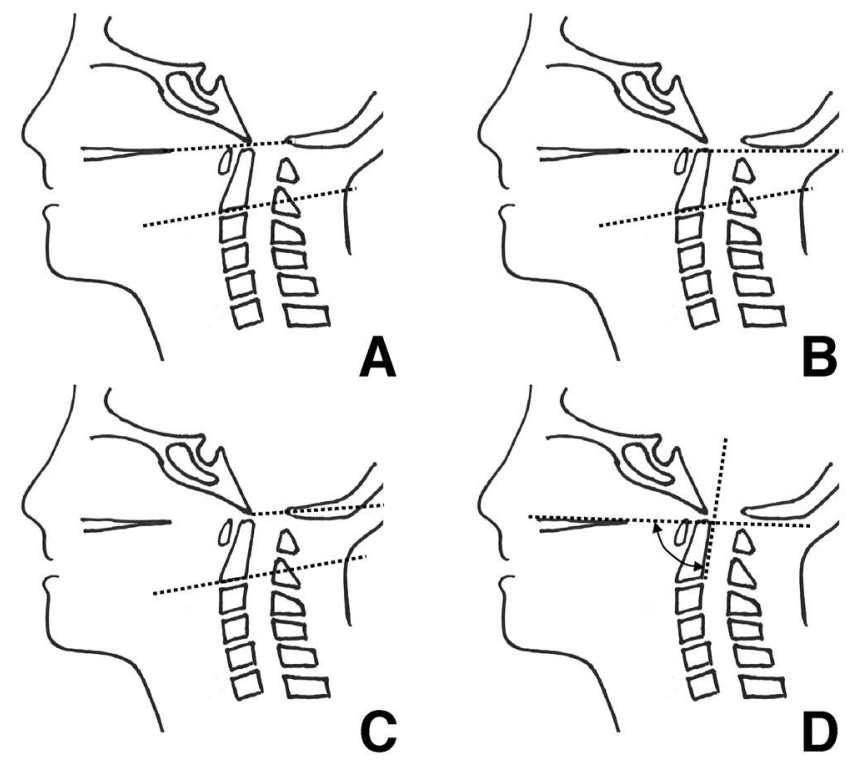

Fig. 1 Various methods used to measure the angle of the craniovertebral junction. A: Angle between the Chamberlain line and the line parallel to the inferior endplate of the C2 vertebra. B: Angle between the McGregor line and the line parallel to the inferior endplate of the C2 vertebra. C: Angle between the McRae line and the line parallel to the inferior endplate of the C2 vertebra. D: Present method showing the angle between the line parallel to the bony palate and the posterior longitudinal line of the $\mathrm{C} 2$ vertebra.

vical fusion is to achieve minimal and rigid internal fixation with sufficient grafting of autologous bone, and we prefer the use of $\mathrm{C} 2$ pedicle or pars interarticularis screws as the anchor screw. ${ }^{14)}$ If the use of C2 pedicle or pars screws was considered risky, C2-3 or C3-4 transarticular screws were used. The clinical profiles of the patients are summarized in Table 1.

After induction of general anesthesia, the May- field three-pin head holder was fixed to the patient's head and the patient was placed prone with the head and neck maintained in the neutral position. The head was then fixed in the neutral position. Fluoroscopic image guidance was used to adjust the angle of the craniovertebral junction to exactly match the preoperative neutral angle by measuring the fixation angle between the line of the bony palate and the posterior longitudinal line of the $\mathrm{C} 2$ vertebral body (Fig. 1D).

For the better understanding of a suitable angle at the craniovertebral junction, 30 normal healthy volunteers, 15 males and 15 females aged from 17 to 77 years (mean 45.1 years), without symptoms of neck pain or limitations of neck movement were examined to determine the normal range. The angle between the line parallel to the bony palate and the posterior longitudinal line of the C2 vertebra was measured on a lateral skull radiograph. The angle ranged from 85 to 118 degrees. The mean angle was 97.1 degrees in males and 102.6 degrees in females, with overall mean \pm standard deviation of $99.9 \pm$ 8.1 degrees.

\section{Illustrative Case}

Case 5: A 44-year-old man presented with a 4-year history of progressive symptoms of neck pain on the left side. He had undergone subtotal resection of a mesenchymal bone tumor around the left jugular foramen and subsequent stereotactic radiosurgery about 4 years previously at another institute. Subsequently, he suffered progressive increase in neck pain. Magnetic resonance imaging showed that the tumor size and intensity had been remained stable over the past 4 years. Computed tomography at our institute showed destruction of the occipital condyle and the $\mathrm{C} 1$ lateral mass on the left side (Fig. 2). The patient underwent occipital-C2 fusion with a pedicle screw placed at $\mathrm{C} 2$ and extensive grafting of the autologous bone. Lateral radiography before and after surgery revealed the exact angle of the craniover- 


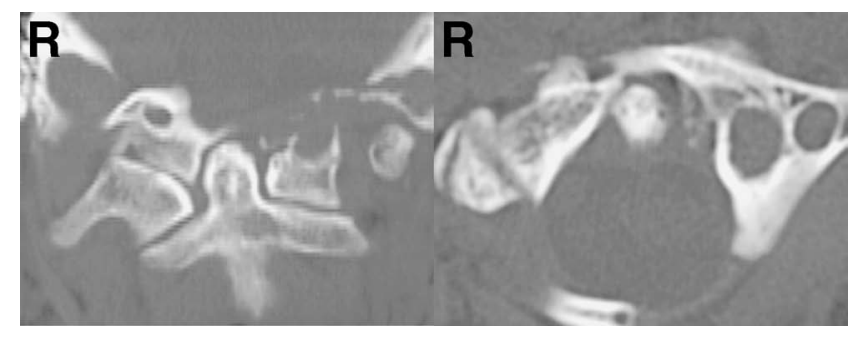

Fig. 2 Case 5. Preoperative computed tomography scans showing destruction of the occipital condyle and the $\mathrm{C} 1$ lateral mass on the left side.
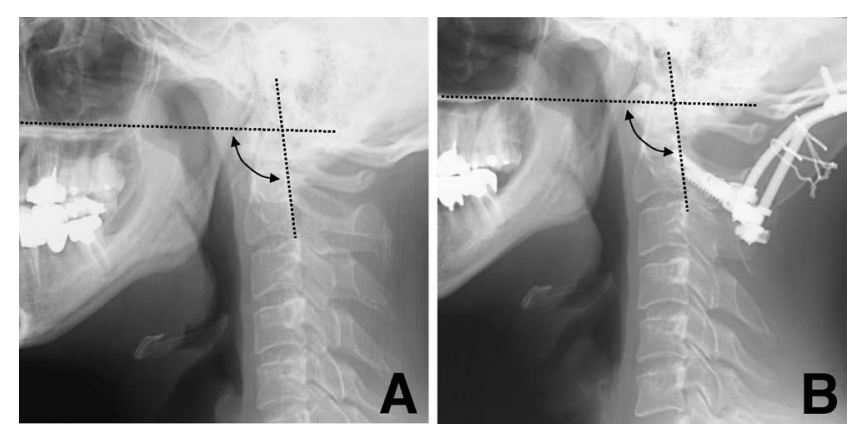

Fig. 3 Case 5. Lateral radiographs before (A) and after surgery (B) revealing the exact adjustment of the angle of the craniovertebral junction to 99 degrees.

tebral junction to be 99 degrees (Fig. 3). After surgery, his neck pain on the left side diminished remarkably and he did not complain of any symptoms of dysphagia or dyspnea.

\section{Discussion}

Various methods have been proposed to measure the angle of the craniovertebral junction based on lateral radiography (Fig. 1A-C). ${ }^{11-13)}$ For example, the angle between the McGregor line and the inferior surface of the axis should be within the range of $0-30$ degrees, taking into consideration the long-term mechanical effects. ${ }^{10)}$ The angles between the inferior endplate of the C2 vertebra and the occiput line were measured using the Chamberlain, McRae, and McGregor lines on the lateral radiographs of 30 healthy volunteers. ${ }^{13)}$ Comparison of the reliability of these three techniques concluded that the McGregor line is the most reproducible and reliable method for measurement of occipitocervical angle. In addition, markers such as the basion for the McRae line and the opisthion for the Chamberlain line were difficult to identify.

We measured the angle between the line parallel to the bony palate and the posterior longitudinal line of the C2 vertebra, which was easy to measure the angle using fluoroscopic imaging. The bony palate and the posterior longitudinal line of the $\mathrm{C} 2$ vertebral body are thought to be readily visualized on standard lateral radiographs or fluoroscopic images. Clear visualization and easy adjustment of the angle are important in practice.

Minimal and rigid internal fixation with adequate grafting of autologous bone are essential in occipitocervical fusion, and the many technical aspects for achieving this are well known, but there has been little discussion of the fixation angle, despite the significant adverse effects of malposition in occipitocervical alignment. Our present method of radiographic measurement to define the neutral position for occipitocervical alignment is simple and reliable, and can be used in clinics as well as in the operating room. However, the present method is not optimal for visualizing the fixation angle. We believe that repeated measurements using different methods to confirm the fixation angle can help the surgeon to determine the appropriate angle of the craniovertebral junction.

\section{References}

1) Abumi K, Takada T, Shono Y, Kaneda K, Fujiya M: Posterior occipitocervical reconstruction using cervical pedicle screws and plate-rod systems. Spine 24: 1425-1434, 1999

2) Dickman CA, Sonntag VK: Posterior C1-C2 transarticular screw fixation for atlantoaxial arthrodesis. Neurosurgery 43: 275-281, 1998

3) Fiore AJ, Haid RW, Rodts GE, Subach BR, Mummaneni PV, Riedel CJ, Birch BD: Atlantal lateral mass screws for posterior spinal reconstruction: technical note and case series. Neurosurg Focus 12: E5, 2002

4) Goel A, Laheri V: Plate and screw fixation for atlantoaxial subluxation. Acta Neurochir (Wien) 129: 47-53, 1994

5) Harms J, Melcher RP: Posterior C1-C2 fusion with polyaxial screw and rod fixation. Spine 26: 2467-2471, 2001

6) Ichinose K, Kozuma S, Fukuyama S, Goto S, Nagata C, Yanagi F: [A case of airway obstruction after posterior occipito-cervical fusion]. Masui 51: 513515, 2002 (Jpn, with Eng abstract)

7) Inamasu J, Kim DH, Klugh A: Posterior instrumentation surgery for craniocervical junction instabilities: an update. Neurol Med Chir (Tokyo) 45: 439-447, 2005

8) Kainuma M, Yamada S: [Postextubation airway obstructive after anesthesia for posterior fusion of the occipital bone and cervical spine]. Masui 34: 15251529, 1985 (Jpn, with Eng abstract)

9) Kawasaki K: [Postoperative airway closure after posterior occipito-cervical fusion]. Rinsho Masui 23: 
1785-1786, 1999 (Jpn, with Eng abstract)

10) Matsunaga S, Onishi T, Sakou T: Significance of occipitoaxial angle in subaxial lesion after occipitocervical fusion. Spine 26: 161-165, 2001

11) McRae DL: Craniovertebral junction, in Newton $\mathrm{TH}$, Potts DG (eds): Radiology of the Skull and Brain. The Skull. St Lois, CV Mosby, 1971, pp 260-274

12) Phillips FM, Phillips CS, Wetzel FT, Gelinas C: Occipitocervical neutral position. Possible surgical implications. Spine 24: 775-778, 1999

13) Shoda N, Takeshita K, Seichi A, Akune T, Nakajima S, Anamizu Y, Miyashita M, Nakamura K: Measurement of occipitocervical angle. Spine 29: 204-208, 2004

14) Takami T, Goto T, Tsuyuguchi N, Nishikawa M, Ohata K: Posterior C1-2 fixation with cancellous screw and rod system for retro-odontoid pseudotumor associated with chronic atlantoaxial subluxation. Technical note. Neurol Med Chir (Tokyo) 47: 189-194, 2007

15) Yoshida M, Neo M, Fujibayashi S, Nakamura T: Upper-airway obstruction after short posterior occipitocervical fusion in a flexed position. Spine 32: 267-270, 2007

Address reprint requests to: Toshihiro Takami, M.D., Department of Neurosurgery, Osaka City University Graduate School of Medicine, 1-4-3 Asahi-machi, Abeno-ku, Osaka 545-8585, Japan.

e-mail: ttakami@med.osaka-cu.ac.jp

\section{Commentary}

The authors have discussed an interesting concept of occipitocervical fixation. They (and some other authors) feel that the fixation should be done in a manner that restores the 'craniocervical' angle of the region. The authors suggest that an abnormal angle following the fixation could lead to a variety of neurological problems that would include problems like dysphagia and breathing disturbances.

Although not mentioned by the authors, the omega angle or the angulation of the odontoid process from the vertical as described by Klaus in 1957 has been a useful guide for measurement of craniocervical angle. ${ }^{2)}$ We described a modified omega angle as the measurement of the angle from the vertical which was affected by the flexion and extension of the neck. ${ }^{1)}$ A line is drawn traversing through the center of the base of the axis parallel to the line of the hard palate. The line of the hard palate was unaffected by the relative movement of the head and the cervical spine during the movement of the neck. Although the authors have used the parameters described by Klaus and by us to some extent, they have not referred to these articles in their reference list. The various lines discussed by the authors, like McGregor's line, Chamberlain's line, and McRae's line, are more classically used to measure basilar invagination rather than for evaluation of the craniocervical angulation. The other measurement that can be useful is the measurement of craniocervical angulation. This is an angle between the Wackenheim's clival line ${ }^{3)}$ and a posterior vertebral line that is a line drawn along the posterior aspect of the body of C2 and odontoid process. ${ }^{4}$

I am not entirely convinced that measurement of the craniocervical angulation can form a guide for fixation during operation. It is difficult for me to conceptualize how the fixation method can be modified to obtain an appropriate craniocervical angle. Moreover the variations in the 'normal' angle are so wide that determination of the most appropriate angle can be impossible. Although the issue has been under discussion, it is unclear to me as to how an abnormal craniocervical angle can cause oropharyngeal and airway passage obstruction.

\section{References}

1) Goel A, Bhatjiwale M, Desai K: Basilar invagination: a study based on 190 surgically treated patients. J Neurosurg 88: 962-968, 1998

2) Klaus E: Rontgendiagnostik der platybasic und basilaren Impression. Fortschr Geb Rontgenstr Nuklearmed 86: 460-469, 1957 (Ger)

3) Thiebaut F, Wackenheim A, Vrousos C: [New median sagittal pneumostratigraphical finding concerning the posterior fossa]. J Radiol Electrol Med Nucl 42: 1-7, 1961 (Fre)

4) VanGilder JC, Menezes AH, Dolan KA: The Craniovertebral Junction and its Abnormalities. Mount Kisco, NY, Futura, 1987, pp 29-68

Atul Goel, M.D. Department of Neurosurgery King Edward VII Memorial Hospital \& Seth G.S. Medical College Parel, Mumbai, India

Takami and colleagues have devised an important method for establishing the angle of the head in performing an occipitocervical instrumentation and stabilization. The necessity of having the patient in a neutral position after this fixation cannot be overemphasized. This issue becomes even more critical in patients who have swallowing problems related to lower cranial nerve palsies after tumor resection. The technique is simple, easily reproducible, and will be very helpful to surgeons.

Chandranath SEN, M.D. Department of Neurosurgery St. Luke's-Roosevelt Hospital Center New York, New York, U.S.A. 